\title{
OS CAMINHOS DA AVALIAÇÃO PSICOLÓGICA NO BRASIL E NO MUNDO: REFLEXÕES PARA UM ESTADO DA ARTE
}

DOI: 10.22289/2446-922X.V7N1A11

\author{
Astrid Sharon Pontes Hasbun ${ }^{1}$ \\ Nilton S. Formiga \\ lonara Dantas Estevam
}

\section{RESUMO}

A avaliação psicológica tem uma relevância histórica para o desenvolvimento da Psicologia como ciência e profissão no Brasil, uma vez que a história da avaliação psicológica no Brasil se confunde com a própria história da Psicologia como ciência e profissão no país, pois ocorre antes mesmo da sua profissionalização com a criação dos cursos de graduação e a previsão de ensino de avaliação psicológica. É possível perceber que o caminho da área de avaliação psicológica no Brasil passou por algumas fases: primeiro um grande interesse pelos testes psicológicos, em seguida um certo descrédito e críticas em virtude da falta de qualidade e de estudos de normatização dos instrumentos usados e a mais atual onde surge um novo florescimento da área. Dessa forma esse trabalho teve como objetivo traçar um histórico reflexivo da área, buscando um entendimento dos caminhos percorridos, das fragilidades e dificuldades enfrentadas na área assim como as possibilidades futuras. O Conselho Federal de Psicologia vem empreendendo esforços no sentido de regulamentar a área através de diversas ações e atuação do Satepsi, bem como diminuir a lacuna ainda encontrada nos aspectos éticos que envolvem a atuação em avaliação psicológica. Este estudo reflete sobre o impacto dessas ações no papel do psicólogo, sua atuação como profissional e possíveis direções futuras para a área. Constata-se assim, que a Psicologia e a área de avaliação psicológica vêm passando por importantes mudanças que tem em vista a qualificação da formação profissional, a valorização das práticas baseadas em evidências científicas e atenção às demandas sociais.

Palavras-chave: Avaliação Psicológica; História da Psicologia; Ética.

\section{THE WAYS OF PSYCHOLOGICAL EVALUATION IN BRAZIL AND THE WORLD: reflections for a state of art}

\section{ABSTRACT}

Psychological assessment has a historical relevance for the development of Psychology as a science and profession in Brazil, since the history of psychological assessment in Brazil is confused with the history of Psychology as a science and profession in the country, as it occurs even before its professionalization with the creation of undergraduate courses and the provision of teaching psychological assessment. However, it is possible to perceive that the path of psychological assessment in Brazil has gone through some phases: first, a great interest in psychological tests,

\footnotetext{
${ }^{1}$ Endereço eletrônico de contato: astrid.sharon@gmail.com

Recebido em 16/12/2020. Aprovado pelo conselho editorial para publicação em 09/03/2021.
} 
then a certain discredit and criticism due to the lack of quality and studies of standardization of the instruments used and the most current where a new flourishing of the area appears. Thus, this work aimed to trace a reflective history of the area, seeking an understanding of the paths taken, the weaknesses and difficulties faced in the area as well as future possibilities. In recent years, the Federal Council of Psychology has been making efforts to regulate the area through various actions and actions of Satepsi, as well as to reduce the gap still found in the ethical aspects that involve acting in psychological assessment. This study reflects on the impact of these actions on the role of the psychologist, his performance as professional and possible future directions for the area. It can be seen, therefore, that Psychology and the area of psychological assessment have undergone important changes aimed at qualifying professional training, valuing practices based on scientific evidence and paying attention to social demands.

Keywords: Psychological Assessment; History of Psychology; Ethics.

\section{LAS FORMAS DE EVALUACIÓN PSICOLÓGICA EN BRASIL Y EL MUNDO: reflexiones para un estado del arte}

\section{RESUMEN}

La evaluación psicológica tiene una relevancia histórica para el desarrollo de la Psicología como ciencia y profesión en Brasil, ya que la historia de la evaluación psicológica en Brasil se confunde con la historia de la Psicología como ciencia y profesión en el país, como ocurre incluso antes de su profesionalización con la creación de cursos de pregrado y la provisión de evaluación psicológica docente. Sin embargo, es posible percibir que el camino de la evaluación psicológica en Brasil ha pasado por algunas fases: primero, un gran interés por las pruebas psicológicas, luego un cierto descrédito y crítica por la falta de calidad y estudios de estandarización de los instrumentos utilizados y la más actual donde aparece un nuevo florecimiento de la zona. Así, este trabajo tuvo como objetivo trazar una historia reflexiva de la zona, buscando el conocimiento de los caminos tomados, las debilidades y dificultades enfrentadas en la zona, así como las posibilidades futuras. En los últimos años, el Consejo Federal de Psicología viene realizando esfuerzos para regular el área a través de diversas acciones y acciones de Satepsi, así como para reducir la brecha que aún se encuentra en los aspectos éticos que implican actuar en la evaluación psicológica. Este estudio reflexiona sobre el impacto de estas acciones sobre el rol del psicólogo, su desempeño como profesional y las posibles orientaciones futuras del área. Se observa, por tanto, que la Psicología y el área de la evaluación psicológica han experimentado cambios importantes encaminados a calificar la formación profesional, valorar las prácticas basadas en la evidencia científica y atender las demandas sociales.

Palabras: clave: Evaluación Psicológica; Historia de la Psicología; Ética.

\section{INTRODUÇÃO}

A avaliação psicológica tem uma relevância histórica para o desenvolvimento da Psicologia como ciência e profissão no Brasil. Em meados do século XIX, o movimento mundial na área de avaliação psicológica reverberou também na história no Brasil. É possível citar nomes como Wilhelm Wundt, com a criação do primeiro laboratório experimental em Leipzig na Alemanha em 1862 e Francis Galton que criou o primeiro laboratório com medidas antropométricas para avaliar funções mentais em 1884.

Rev. Psicol Saúde e Debate. Mar., 2021:7(1): 149-170. 
Em seguida, James Mackeen Cattell cunha o termo "testes mentais" e em 1890 anuncia a sua bateria de testes voltada para a avaliação das diferenças individuais e de desempenho acadêmico de crianças que foi inspirada em Wundt e Galton (cf. Faiad, Pasquali, \& Oliveira, 2019; Wechsler, Hutz, \& Primi, 2019). Segundo Alchieri e Cruz (2003), neste período no Brasil, a avaliação psicológica estava relacionada a um modelo médico, que era justamente o que acontecia na Psicologia moderna no mundo.

No início do século $\mathrm{XX}$, o desenvolvimento dos testes traz um grande avanço teórico e prático. Charles Spearman, também influenciado por Galton, dá origem a psicometria clássica e dentre suas importantes contribuições está a publicação do manuscrito sobre o fator $G$ de inteligência. De acordo com Pasquali (2010) a partir dessa época, os interesses da área passam a ser a medida de predição dos contextos da educação e saúde.

Em 1904 Alfred Binet propõe o modelo do fator geral e de um teste capaz de identificar crianças com problemas de aprendizagem, denominou-o de Escala de Inteligência, que se tornou importante marco nos testes psicológicos (Bueno \& Peixoto, 2018; Faiad, Pasquali, \& Oliveira, 2019). Segundo Wechsler et al (2019), é possível que Binet tenha planejado o primeiro serviço de psicologia aplicada que foi instalado no Rio de Janeiro, por volta de 1900, denominado de laboratório Pedagogium. O laboratório tinha o objetivo de divulgar e desenvolver novas metodologias pedagógicas e sua escala, Binet-Simon, foi a primeira a ser amplamente administrada no país nos meados de 1910.

Entre 1910 e 1930 foi a era dos testes de Inteligência. Nessa mesma época há impacto da I Grande Guerra Mundial com a necessidade de seleção coletiva, rápida e eficiente para avaliações de recrutas do exército. Deste processo surgem os testes Army Alpha e Beta (Faiad et al, 2019; Pasquali, 2010).

De acordo com Noronha e Alchieiri (2002) os primeiros testes desta época no Brasil estavam voltados para pesquisas e aplicabilidade dos instrumentos para avaliação da inteligência, seleção, indicação e avaliação de habilidades para o trabalho. Segundo Pasquali (2010), de 1930 a 1940 foi demarcado pela década da análise fatorial; tornando-se, na concepção de Faiad et al (2019), um longo período sob o uso desta técnica, a qual, foi a mais utilizada no mundo no contexto de avaliação psicológica.

Pesquisas no campo da inteligência e personalidade avançaram muito nesse período e Louis Leon Thurstone faz sua contribuição ao propor que a inteligência consistia em sete fatores conhecidos como habilidades mentais primárias (Faiad et al, 2019). No Brasil também houve um ritmo intenso de investigações e aplicabilidades acompanhando o que acontecia no mundo. Os instrumentos psicológicos chegavam ao país e eram padronizados de acordo com as exigências da época.

Entre 1940 e 1950 no Brasil houve um interesse maior pelas temáticas de Psicologia do desenvolvimento, avaliação da personalidade, orientação profissional, desenvolvimento infantil, Rev. Psicol Saúde e Debate. Mar., 2021:7(1): 149-170. 
intervenção grupal e adaptação de instrumentos (Noronha \& Alchieri, 2002). Nesta década, há a implantação do Instituto de Seleção e Orientação Profissional (ISOP) no Rio de Janeiro que tinha como objetivo realizar a seleção de pessoas tendo como base os resultados em testes psicológicos (Noronha \& Reppold, 2010). Com isso, deve-se ao ISOP a origem dos atuais "exames psicotécnicos" que foram iniciados para a avaliação de motoristas do Rio de Janeiro.

Um nome que também se destaca na área de avaliação psicológica, nesse período, foi o psicólogo espanhol Myra y Lopes que segundo Wechsler et al (2019) coordenou o ISOP durante 17 anos, publicou o primeiro periódico científico dedicado exclusivamente à Psicologia (Arquivo Brasileiro de Psicotécnica) e junto com Lourenço Filho fundou a Sociedade Brasileira de Psicotécnica, que posteriormente ficou conhecida como Sociedade Brasileira de Psicologia Aplicada em 1995.

O advento da II Grande Guerra Mundial suscitou a necessidade de testes de seleção de soldados e as bases psicométricas de testagem ainda estavam em seu estágio inicial e, com isso, a qualidade psicométrica dos instrumentos era ainda duvidosa. Esse grande interesse na utilização de testes não foi acompanhado por um maior investimento em pesquisas e produção de material psicológico. Inicia então no Brasil, uma fase de estagnação em relação a construção e adaptação dos instrumentos utilizados, ocasionando o uso de instrumentos estrangeiros apenas traduzidos sem estudos de validade ou normatização para a realidade brasileira (Bueno \& Peixoto, 2018; Nakano \& Alves, 2019).

\section{DESENVOLVIMENTO}

Assim, os testes que inicialmente contribuíram para o estabelecimento da Psicologia como ciência, passaram a ser motivo de questionamento de sua eficiência em virtude das deficiências psicométricas, do possível caráter excludente, do uso baseado em interpretações estatísticas e não psicológicas e por serem a única fonte de informação para a realização de diagnósticos. Esse questionamento recai inclusive sobre a capacidade da Psicologia em dar respostas esperadas à sociedade (Bueno \& Peixoto, 2018; Bueno \& Ricarte, 2017)

Para Nakano e Alves (2019) a história da avaliação psicológica no Brasil se confunde com a própria história da Psicologia como ciência e profissão no país, pois ocorre antes mesmo da sua profissionalização com a criação dos cursos de graduação e a previsão de ensino de avaliação psicológica. Após o reconhecimento da profissão, tem-se nas décadas seguintes a consolidação de cursos de Pós graduação com linhas de pesquisa em avaliação psicológica e a criação de laboratórios de avaliação psicológica.

Um grande marco para consolidação da área de avaliação psicológica e da Psicologia no Brasil foi a aprovação da Lei no 4.119/1962 que regulamentada pelo Decreto de ํㅜ 53.464/1964 
institui a profissão de psicólogo no país. Entre outras questões, o decreto define em seu art. $4^{\circ}$ que são funções do psicólogo utilizar métodos e técnicas psicológicas com o objetivo de:

a) diagnóstico psicológico;

b) orientação e seleção profissional;

c) orientação psicopedagógica;

d) solução de problemas de ajustamento. Determina ainda que é da competência do Psicólogo a colaboração em assuntos psicológicos ligados a outras ciências.

A referida lei (Brasil, 1962; Brasil, 1964) versa que constitui função privativa do Psicólogo a utilização de métodos e técnicas psicológicas com os seguintes objetivos:

a) diagnóstico psicológico;

b) orientação e seleção profissional;

c) orientação psicopedagógica;

d) solução de problemas de ajustamento.

Ainda em 1962 também foi emitido o Parecer de n 403 do Conselho Federal de Educação que institui a duração do curso de graduação em Psicologia com seu currículo mínimo e contemplava as ementas e disciplinas voltadas para a avaliação psicológica (Nakano \& Alves, 2019). Nesta mesma época passou a ser exigido pelo Conselho Nacional de Trânsito (CONATRAN) a obrigatoriedade do "exame psicotécnico" para todas as pessoas que requisitasse a habilitação para dirigir (Wechsler et al, 2019)

A partir de 1980 tem-se a era da psicometria moderna que segundo Nunes e Primi (2005) inicia com o surgimento da Teoria de Resposta ao Item (TRI), a qual, segundo Pasquali (2010), surge como um recurso complementar às limitações da Teoria Clássica e não como forma de substituir a psicometria como um todo. Sendo assim segundo este autor seria incorreto denominar essa como a era da TRI.

$\mathrm{Na}$ década de 2000, estudos científicos buscam tirar o foco do sofrimento psíquico e investigar os aspectos de preservação da saúde mental como perdão, alegria e felicidade. Essa nova corrente, conhecida como Psicologia Positiva, busca evidências de validade de medidas de bem estar subjetivo e/ ou forças de caráter através de técnicas e provas próprias (Faiad et al, 2019).

É possível perceber que o caminho da área de avaliação psicológica no Brasil passou por algumas fases: primeiro um grande interesse pelos testes psicológicos, em seguida um certo descrédito e críticas em virtude da falta de qualidade e de estudos de normatização dos instrumentos usados e a mais atual onde surge um novo florescimento da área.

Fazendo um recorte sobre as principais dificuldades enfrentadas na área de avaliação psicológica nas últimas décadas no Brasil é importante sinalizar, dentre outras, à confusão entre os conceitos de avaliação e testagem psicológica e a má qualidade psicométrica dos instrumentos. $A$ má qualidade psicométrica aconteceu em virtude da introdução de instrumentos e técnicas no Brasil sem serem devidamente estudados e validados para a realidade brasileira (Faiad et al, 2019).

Rev. Psicol Saúde e Debate. Mar., 2021:7(1): 149-170. 
De acordo com os autores supracitados, a confusão entre avaliação e testagem psicológica é intrínseca ao próprio desenvolvimento da Psicologia como ciência, uma vez que um dos caminhos pelos quais a Psicologia poderia conquistar o status científico era através do desenvolvimento de instrumentos de medida. Uma outra dificuldade enfrentada pela área, segundo Bueno e Peixoto (2018), foi a criação acelerada de vários cursos de Psicologia e a falta de professores qualificados para o ensino da avaliação psicológica, o que resultou em deficiência na formação e profissionais sem qualificação técnica para a atuação.

A partir desta perspectiva, atribui-se a imagem de que os testes servem para rotular e estigmatizar as pessoas ao invés de ajudar em seu desenvolvimento e os próprios profissionais da Psicologia começam a propor o seu abandono como prática por considerarem-na como nociva para a Psicologia (Noronha et al, 2002). Vários processos éticos surgem no CFP e na justiça em virtude da comercialização e uso de testes com propriedades psicométricas desconhecidas ou não informadas no manual do instrumento (Muniz, 2018).

Dessa forma, a área de Avaliação Psicológica passou por vários desafios no que se refere a qualificação de profissionais e criação de instrumentos com características psicométricas confiáveis. Com o intuito de propor políticas que ajudassem a melhorar a qualidade das práticas de avaliação psicológica, o CFP definiu através da Resolução no 25 de 2001 que o teste psicológico é método privativo do psicólogo e regulamentou sua elaboração, uso e comercialização definindo critérios mínimos que os instrumentos deveriam atender para que fossem aprovados para uso profissional.

Além disso o CFP instituiu em 2003 a Comissão Consultiva em Avaliação Psicológica (CCAP), composta por pesquisadores e profissionais da área, cuja função é discutir e propor diretrizes, normas e resoluções na área de avaliação psicológica, além de conduzir o processo de avaliação dos instrumentos psicológicos submetidos ao Sistema de Avaliação de Instrumentos Psicológicos (SATEPSI). Os membros dessa comissão são renovados a cada gestão do CFP e atualmente é formada por pesquisadores e representantes legais ligados à Associação Brasileira de Rorschach e Métodos Projetivos (AsBRo) e ao Instituto Brasileiro de Avaliação Psicológica (IBAP) (Bueno \& Peixoto, 2018; Wechsler, 2019).

De 2001 até os dias atuais, o CFP tem se preocupado com a regulamentação da área, instituindo resoluções específicas para a atuação do profissional psicólogo, sendo as mais recentes as resoluções CFP no 09/2018 e a CFP 06/2019:

- A primeira resolução estabelece diretrizes para a realização da avaliação psicológica no exercício profissional do psicólogo, regulamenta SATEPSI e revoga as resoluções CFP no 002/2003, CFP ํo 006/2004 e CFP ํㅜ 005/2012 e Notas Técnicas no 01/2017 e no 02/2017;

- A segunda resolução institui regras para a elaboração de documentos escritos produzidos pelo psicólogo no exercício profissional e revoga as Resoluções CFP nํ15/1996, CFP no 07/2003 
e CFP nº 04/2019. No quadro abaixo há uma síntese das principais ações do CFP com o propósito de desenvolvimento da área no período de 2001 a 2019.

Quadro 1: Principais ações do CFP para área de avaliação psicológica entre 2001 e 2019

\begin{tabular}{|c|c|}
\hline Ano & Ação \\
\hline \multirow[b]{2}{*}{2001} & Discussões preliminares para criação do SATEPSI. \\
\hline & $\begin{array}{l}\text { Resolução CFP no 25/2001 - Define teste psicológico como método de } \\
\text { avaliação do psicólogo e regulamenta sua elaboração, comercialização e uso. }\end{array}$ \\
\hline \multirow{3}{*}{2003} & Criação do SATEPSI. \\
\hline & $\begin{array}{l}\text { Resolução CFP no 002/2003 - Regulamenta o uso, a elaboração e a } \\
\text { comercialização de testes psicológicos. }\end{array}$ \\
\hline & $\begin{array}{l}\text { Resolução CFP nº 007/2003 - Institui o manual de elaboração de documentos } \\
\text { escritos produzidos pelo psicólogo, decorrentes de avaliação psicológica. }\end{array}$ \\
\hline 2005 & $\begin{array}{l}\text { De } 2005 \text { a } 2010 \text { - Visita da CCAP a todos os CRPs para divulgação do } \\
\text { SATEPSI }\end{array}$ \\
\hline 2007 & Elaboração de cartilha sobre Avaliação Psicológica. \\
\hline 2010 & $\begin{array}{l}\text { Elaboração do Relatório "Avaliação Psicológica: diretrizes na regulamentação } \\
\text { da profissão". }\end{array}$ \\
\hline \multirow{3}{*}{2011} & Treinamento aos pareceristas ad hoc do SATEPSI \\
\hline & Instituição do ano temático da Avaliação Psicológica em 2011/2012; \\
\hline & $\begin{array}{l}\text { Lançamento do Prêmio Profissional "Avaliação Psicológica na perspectiva dos } \\
\text { direitos humanos"; }\end{array}$ \\
\hline \multirow{3}{*}{2012} & Organização do Seminário do ano temático da Avaliação Psicológica \\
\hline & $\begin{array}{l}\text { Publicação do relatório "Ano da avaliação psicológica: textos geradores" e } \\
\text { "Relatório do ano temático da avaliação psicológica 2011/2012. }\end{array}$ \\
\hline & $\begin{array}{l}\text { Atualização da resolução CFP no } 002 / 2003 \text { através da publicação da resolução } \\
\text { CFP no } 005 / 2012 \text { - Dispõe sobre requisitos éticos e de defesa dos direitos } \\
\text { humanos na construção de testes psicológicos. }\end{array}$ \\
\hline \multirow[b]{2}{*}{2013} & ore Avaliação Psicológic \\
\hline & $\begin{array}{l}\text { Criação da campanha "A banalização dos testes psicológicos prejudica toda a } \\
\text { sociedade". }\end{array}$ \\
\hline \multirow[b]{2}{*}{2015} & $1^{\circ}$ edital para pareceristas ad hoc do SATEPSI. \\
\hline & $\begin{array}{l}\text { Resolução CFP no 034/2015 - Define e regulamenta a comissão consultiva em } \\
\text { avaliação psicológica (CCAP). }\end{array}$ \\
\hline \multirow{2}{*}{2016} & a pareceristas ad hoc do SATEPSI. \\
\hline & erantes da CCAP nas cinco regiões geopolític \\
\hline \multirow{3}{*}{2017} & stas ad hoc do SATEPSI. \\
\hline & $\begin{array}{l}\text { /2017 - Altera a resolução CFP no } 034 / 2 \\
\text { lo consultiva em avaliação psicológica (C }\end{array}$ \\
\hline & Publicação das notas técnicas no $001 / 2017$ e no $002 / 2017$. \\
\hline \multirow[t]{2}{*}{2018} & $\begin{array}{l}\text { Resolução CFP no 009/2018 - Estabelece diretrizes para a realização de } \\
\text { avaliação psicológica no exercício profissional da psicóloga e do psicólogo, } \\
\text { regulamente o Sistema de Avaliação de testes psicológicos - SATEPSI e } \\
\text { revoga as Resoluções no 002/2003, no 006/2004, nº 005/2012 e notas técnicas } \\
n^{\circ} 001 / 2017 \text { e n 002/2017 }\end{array}$ \\
\hline & $\begin{array}{l}\text { Resolução CFP no } 011 / 2018 \text { - Regulamenta a prestação de serviços } \\
\text { psicológicos realizados por meios de tecnologias da informação e da } \\
\text { comunicação e revoga a Resolução CFP N.11/2012 }\end{array}$ \\
\hline 2019 & $\begin{array}{l}\text { Resolução CFP no } 001 / 2019 \text { - Institui normas e procedimentos para a perícia } \\
\text { psicológica no contexto do trânsito e revoga as resoluções CFP nำ007/2009 e } \\
009 / 2011\end{array}$ \\
\hline
\end{tabular}




\begin{tabular}{|c|}
\hline 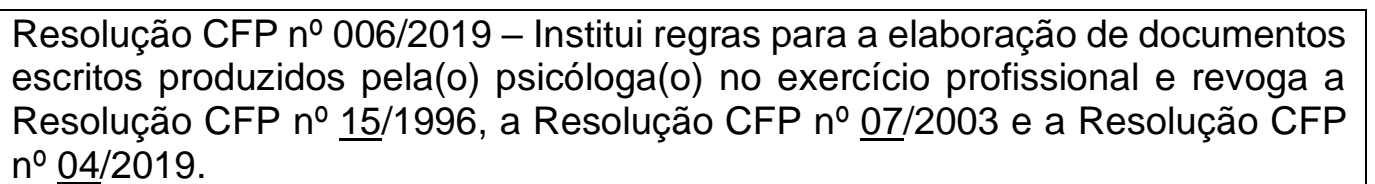 \\
\hline $\begin{array}{l}\text { Resolução CFP } \mathrm{n}^{0} \quad 10 / 2019-\text { Define e } \text { regulamenta procedimentos } \\
\text { administrativos das reuniões da } \\
\text { em Avaliação Psicológica e estabelece critérios de publicidade dos materiais } \\
\text { provenientes de tais reuniões }\end{array}$ \\
\hline $\begin{array}{l}\text { Resolução CFP no 17/2019 - Altera a Resolução CFP no 03/2017, que define e } \\
\text { regulamenta a Comissão Consultiva em Avaliação Psicológica }\end{array}$ \\
\hline $\begin{array}{l}\text { Resolução CFP no } 18 / 2019 \text { - Reconhece a Avaliação Psicológica como } \\
\text { especialidade da Psicologia e altera a Resolução CFP no } 13 \text {, de } 14 \text { de setembro } \\
\text { de 2007, que institui a Consolidação das Resoluções relativas ao Título } \\
\text { Profissional de Especialista em Psicologia. }\end{array}$ \\
\hline
\end{tabular}

Fontes: Linha do tempo SATEPSI (CFP, 2019); site CFP 2020. Elaborado pelos autores.

Constata-se assim, que a Psicologia e a área de avaliação psicológica vêm passando por importantes mudanças que tem em vista a qualificação da formação profissional, a valorização das práticas baseadas em evidências científicas e atenção às demandas sociais. $\mathrm{Na}$ área da avaliação psicológica, especificamente, é possível perceber a ampliação de pesquisas científicas com os testes psicológicos, o crescimento de grupos de pesquisa na área e um maior interesse dos profissionais no domínio dos preceitos e técnicas da área. Esses acontecimentos têm trazido como consequência um resgate da credibilidade do uso dos testes no país (Reppold \& Noronha, 2018).

\subsection{Satepsi: Do controle instrumental à ética da avaliação da qualidade de escalas de medida}

Um dos problemas que o CFP enfrenta são as denúncias de infração ao Código de Ética do Psicólogo pelos profissionais ao realizarem avaliações psicológicas (Zaia, Oliveira, \& Nakano, 2018). Esse tipo de queixa é recorrente em relação aos profissionais da psicologia por parte da sociedade e em parte isso ocorre em virtude de a avaliação psicológica ser um dos serviços mais realizados e solicitados pela sociedade. Além disso, em muitos casos, a avaliação psicológica traz consequências de grandes impactos para a vida dos sujeitos envolvidos, como é o caso de concursos públicos (Primi, 2018).

De acordo com Noronha e Reppold (2010,2018), no final de 1990 a avaliação psicológica no Brasil sofreu duras críticas em virtude da qualidade dos instrumentos psicológicos disponíveis no país naquela época e da forma como as avaliações eram realizadas. Em função da limitação na formação, notava-se um problema na seleção dos instrumentos e em alguns casos havia instrumentos que necessitavam de maior fundamentação científica para sua utilização, pois havia um desconhecimento do amplo processo de construção dos testes e pouca estima à estatística.

Como forma de normatizar os instrumentos e garantir a qualidade técnica e ética dos instrumentos comercializados para a realização de avaliação psicológica, o CFP propõe em 2001 e implementa em 2003 o SATEPSI com o objetivo de avaliar a qualidade técnico-científica de Rev. Psicol Saúde e Debate. Mar., 2021:7(1): 149-170. 
instrumentos psicológicos para uso profissional, a partir da verificação objetiva de um conjunto de requisitos técnicos e divulgar à comunidade e aos psicólogos.

A partir da criação do SATEPSI inicia-se um movimento com o intuito de valorizar a área de Avaliação Psicológica com algumas medidas encabeçadas pelo CFP como, por exemplo, a avaliação de todos os testes psicológicos existentes no país. Para Bueno e Peixoto (2018) a proposta do CFP vem de uma busca de fortalecimento do compromisso da Psicologia com a sociedade através do monitoramento da qualidade técnica dos instrumentos de avaliação utilizados pelos psicólogos. O SATEPSI trata-se de um sistema contínuo de avaliação dos testes psicológicos que envolve: a) a regulamentação da área, b) a análise dos requisitos mínimos que um teste psicológico precisa apresentar, c) a elaboração de listas dos testes considerados favoráveis ou desfavoráveis para uso profissional e d) a divulgação dessas informações à comunidade (Reppold \& Noronha, 2018).

Os requisitos mínimos para os testes foram elaborados a partir dos guidelines propostos pela Internacional Test Commission, American Educational Research Association, American Psychological Association and National Council on Measurement in Education e Cartilha de Avaliação Psicológica elaborada pelo CFP em 2013 (CFP, 2018, p.04)

O SATEPSI se constitui em um dos fatores mais importantes para a retomada do desenvolvimento da área de avaliação psicológica no Brasil e importante indutor de discussões e aprimoramento da área (Mansur-Alves, Silva e Fernandes, 2016; Primi, 2018).

Considerando a reflexão exposta no parágrafo acima, é importante destacar que em 2002, logo após sua implantação, dos 91 testes submetidos ao SATEPSI, 61,5\% foi considerado desfavorável para o uso profissional e apenas 28\% dos instrumentos comercializados até 2003 apresentavam estudos de precisão, validade e padronização (Noronha, Primi, \& Alchieri, 2004).

Em novembro de 2020, em pesquisa no link do SATEPSI ${ }^{1}$ no site do CFP, constam 157 testes favoráveis para uso profissional em detrimento dos 30 aprovados em 2003. Além disso, o sistema é reconhecido por órgãos internacionais vinculados à área como American Psychological Association e a International Test Commission como pioneiro na certificação de instrumentos psicológicos baseados em critérios internacionais de qualidade e servindo de modelo a ser implantado em vários países da América do Sul e aqueles de língua portuguesa (Primi, 2010; Reppold \& Noronha, 2018).

Desde sua criação, o SATEPSI mantém uma lista atualizada de todos os testes psicológicos que atendem os requisitos mínimos exigidos pelo CFP, ou seja, que apresentam características psicométricas adequadas e são aprovados para o uso profissional. Bem como há uma listagem dos testes não aprovados e aqueles que se encontram em análise.

\footnotetext{
${ }^{1}$ https://satepsi.cfp.org.br/
} 
A lista completa pode ser acessada on-line através do link http://satepsi.cfp.org.br. Além da lista dos testes psicológicos constam no link as resoluções, notas técnicas e documentos de referência de avaliação psicológica fornecendo fundamentação técnica e científica aos profissionais da área.

Com a promulgação da resolução CFP 009/2018 há uma continuidade no estabelecimento das diretrizes para a realização da avaliação psicológica no exercício profissional e regulamentação do SATEPSI revogando as resoluções 002/2003, 006/2004 e 005/2012 e notas técnicas 01/2017 e 02/2017.

Em relação à submissão de testes ao SATEPSI, a Resolução CFP no 09/2018 delimita quais são os critérios mínimos obrigatórios para que sejam reconhecidos para uso profissional:

a) apresentação de fundamentação teórica, com especial ênfase na definição do(s) construto(s), descrevendo seus aspectos constitutivo e operacional;

b) Definição dos objetivos do teste e contexto de aplicação, detalhando a população-alvo;

c) Pertinência teórica e qualidade técnica dos estímulos utilizados nos testes;

d) Apresentação de evidências empíricas sobre as características técnicas dos itens do teste, exceto para os métodos projetivos/expressivos;

e) Apresentação de evidências empíricas de validade e estimativas de precisão das interpretações para os resultados do teste, caracterizando os procedimentos e os critérios adotados na investigação;

f) Apresentação do sistema de correção e interpretação dos escores, explicitando a lógica que fundamenta o procedimento, em função do sistema de interpretação adotado;

g) apresentação explícita da aplicação e correção para que haja a garantia da uniformidade dos procedimentos (CFP, 2018, p.05).

A submissão para análise dos testes é feita através do SATEPSI, condicionada à indicação de responsável técnico com CRP ativo. Após submissão, os testes são avaliados pela CCAP que designa 02 pareceristas para análise do teste com prazo de 20 dias a partir do aceite e que pode ser renovado por mais 20 dias para emissão de parecer. Um relator da CCAP fará a análise de ambos os pareceres e emitirá um relatório conclusivo a ser analisado pela CCAP.

Para que um parecer seja favorável o instrumento deve receber conceitos equivalentes a excelente ou bom em todas as áreas avaliadas (Bueno \& Peixoto, 2018). Os testes com parecer desfavorável podem ser reapresentados a qualquer tempo para nova avaliação. Em relação aos testes considerados favoráveis, os estudos de validade, precisão e normas dos testes psicológicos tem o prazo máximo de 15 (quinze) anos, a contar da data da aprovação do teste psicológico pela plenária do CFP. 
No caso de novas versões favoráveis, a versão antiga pode ser utilizada até a data final de vencimento de seus estudos de normatização, validade e precisão. Se dentro do prazo previsto não houver apresentação de revisão, o teste perderá a condição de uso e será excluído da lista do SATEPSI. Todos os testes psicológicos se enquadram nessas normas e os manuais devem conter a informação que sua comercialização e uso é exclusivo para psicólogos.

A importância de uma iniciativa como o SATEPSI se dá principalmente pelo fato que a avaliação psicológica pode ter efeitos importantes na vida das pessoas, podendo estes serem positivos ou negativos dependendo de como os procedimentos são realizados.

Reppold et al (2017) afirmam que os manuais dos testes psicológicos publicados nos últimos anos possuem mais informações e encontram-se mais organizados de modo mais sistemático, o que pode ser, de certa forma, compreendido como um processo de avanço a partir do SATEPSI.

Entretanto, o SATEPSI também recebe críticas. Uma delas é que os critérios mínimos adotados como referência para avaliação dos instrumentos são pouco exigentes (Primi \& Nunes, 2010). Uma das consequências apontadas é que não importa a quantidade ou qualidade dos estudos apresentados, se eles atendem aos critérios mínimos são classificados como favoráveis ao uso profissional.

A proposta apresentada por Bueno e Peixoto (2018) seria ampliar o leque de denominações para instrumentos favoráveis, considerando o número e a diversidade dos estudos de fidedignidade, padronização e validade classificando-os em níveis de excelente, adequado ou mínimo.

\subsection{Avaliação psicológica: da prática científica à profissional}

Wechsler et al (2019) afirmam que a avaliação psicológica é uma das mais importantes áreas da Psicologia, pois possibilita a compreensão do funcionamento psíquico e comportamental do indivíduo. Perspectiva conceitual, a qual, foi corroborada por Reppold, Zanini e Noronha (2019, p.15) ao definir que a avaliação psicológica é "um campo do conhecimento, com pressupostos teóricos e metodológicos próprios e uma prática profissional que perpassa diversas áreas da Psicologia" (p.15).

Configurando-se como uma prática privativa e fundamental para profissionais de psicologia de diversas áreas e pode ser realizada em vários contextos como, por exemplo, aquisição de habilitação, demandas judiciais, escolas, sistema prisional, avaliações clínicas, processos seletivos em organizações, orientações profissionais, para manuseio de arma de fogo e outros onde se fizer necessário a compreensão do comportamento humano. Ou seja, a avaliação psicológica busca fornecer informações e responder demandas específicas em contextos diversos.

Para Reppold et al (2019) toda atividade profissional do psicólogo envolve uma avaliação do fenômeno observado e uma vez que a prática profissional é pautada cientificamente, essa 
observação se constitui em uma avaliação psicológica mesmo que realizada através de diferentes métodos de investigação.

Sendo assim, a avaliação psicológica é uma prática intrínseca ao exercício profissional de qualquer psicólogo uma vez que para a condução de qualquer intervenção psicológica é necessária uma análise do indivíduo e de suas demandas (Nakano \& Alves, 2019). Contudo a avaliação psicológica que está implícita na atuação do profissional psicólogo é diferente da avaliação psicológica como procedimento mais amplo destinado essencialmente à prática avaliativa.

O conceito de avaliação psicológica como se percebe, atualmente, passou por uma evolução ao longo dos anos, passando de uma coleta de dados com intuito de descrever comportamentos para um processo amplo e estruturado que através de métodos e técnicas visa obter informações para uma tomada de decisão mais assertiva.

Wechsler (1999) fala da avaliação psicológica como um processo científico de coleta de dados e interpretação de informações, realizado por meio de instrumentos psicológicos com a finalidade de obter informações a respeito de diferentes dimensões psicológicas do indivíduo, como: capacidades cognitivas e sensório-motoras, componentes sociais, emocionais, afetivos a fim de que sejam tomadas determinadas decisões.

Segundo Pasquali (2001) a avaliação psicológica é uma coleta de dados a partir dos vários métodos, técnicas e instrumentos e tem como objetivo descrever e classificar as atitudes e comportamentos de uma pessoa ou grupo.

Essa descrição e classificação parte do pressuposto que a partir da avaliação da personalidade é possível predizer o que uma pessoa fará em determinada situação, ou seja, como ela irá desempenhar uma determinada atividade, qual será a qualidade de suas relações e como desenvolverá seus vínculos afetivos, entre outros (Pasquali, 2001).

Um conceito mais amplo e atual é o trazido pelo CFP através da Resolução no 09/2018, no seu artigo $1^{\circ}$, no qual a avaliação psicológica é descrita "como um processo estruturado de investigação de fenômenos psicológicos, composto de métodos, técnicas e instrumentos, com o objetivo de prover informações à tomada de decisão, no âmbito individual, grupal ou institucional, com base em demandas, condições e finalidades específicas". É uma dedução a respeito de atributos psicológicos não observáveis diretamente, mas que podem ser pressupostos a partir de uma avaliação de comportamentos que representam esse atributo. (Primi, 2018; Reppold et al, 2019).

A mais recente atualização do CFP sobre a área de avaliação psicológica foi a resolução CFP nํ0 009/2018 que regulamenta a avaliação psicológica como prática profissional no Brasil e esclarece que o psicólogo pode decidir quais métodos, técnicas e instrumentos serão utilizados em cada avaliação. Entretanto, enfatiza que essa escolha deve conter respaldo científico e atender à regulamentação da profissão (CFP, 2018). 
A escolha dos instrumentos e métodos é determinada pela demanda da avaliação, da situação avaliativa, dos recursos disponíveis e da competência e formação do avaliador. O uso de testes psicológicos nas avaliações tende a converter-se em resultados e encaminhamentos mais assertivos. Entretanto, esse resultado é condicionado à qualidade dos testes e à formação do psicólogo (Reppold et al, 2019).

A avaliação psicológica não pode ser considerada como um processo que reduz o indivíduo avaliado a um número na tentativa de enquadrá-lo em algum padrão de comportamento predominante. Efetivamente se mostra como um processo dinâmico que pode ou não incluir o uso de testes psicológicos, mas que envolve a confluência das informações obtidas através de diversos métodos e instrumentos de investigação reconhecidos cientificamente respeitando os preceitos da profissão (Muniz, 2018).

A avaliação psicológica visa fazer inferências a respeito de um constructo seja ele de personalidade, inteligência etc. Um constructo nada mais é que um atributo não observável e que pode surgir no comportamento observado na testagem (Primi, 2018). De forma geral, aos destacar sobre os métodos e instrumentos de avaliação é preciso apresentar uma distinção do que é um processo de avaliação psicológica e uma testagem psicológica. Os testes psicológicos são um dos recursos de uma avaliação psicológica, mas não são as únicas fontes de informação em um processo avaliativo.

Sendo assim, um processo amplo de avaliação psicológica envolve várias etapas e a utilização de vários métodos e fontes como entrevistas, análise de documentos, dinâmicas de grupo, podendo ou não utilizar os testes psicológicos. Já a testagem norteia suas análises e resultados apenas nos testes psicológicos que segundo a resolução CFP № 009/2018 abarcam instrumentos como escalas, inventários, questionários e métodos projetivos/expressivos para fins de padronização.

Entretanto, é importante salientar que embora o uso de testes não seja imprescindível em uma avaliação psicológica, o uso de instrumentos normatizados e com evidências de validade e precisão constituem recursos de extrema importância para o psicólogo considerando o risco de interpretação subjetiva que a entrevista, a observação e as técnicas não normatizadas podem trazer. Além disso, é possível comparar o avaliando com seu grupo normativo e ou com seu próprio desempenho em tarefas prévias (Reppold \& Noronha, 2018).

Uma das mudanças apresentadas na Resolução CFP nº 009/2018 é a questão das "fontes fundamentais" e "fontes complementares" de informação. Entre as consideradas fontes fundamentais estão os testes psicológicos com parecer favorável do SATEPSI, a entrevista, a anamnese e/ou protocolo ou registros de observação.

Já as fontes secundárias são técnicas e instrumentos não psicológicos que possuem respaldo científico e que respeitem o código de ética e as garantias da legislação da profissão, bem 
como documentos técnicos, como protocolos ou relatórios de equipes multiprofissionais (CFP, 2018, p.03)

As informações coletadas nas avaliações psicológicas a partir das fontes fundamentais e secundárias podem ser consideradas como preditivos de comportamentos futuros e a decisão que o psicólogo tomará será baseada na junção dessas informações.

Contudo, o CFP afirma que "como o comportamento humano é resultado de uma complexa teia de dimensões inter-relacionadas que interagem para produzi-lo, é praticamente impossível entender e considerar todas as nuances e relações a ponto de prevê-lo deterministicamente" (CFP, 2013, p.15). Dessa forma, é possível predizer um comportamento a partir de traços que se apresentam nas avaliações, mas essa predição não pode ser considerada de forma determinística uma vez que se trata não só da estrutura, mas também da dinâmica de personalidade.

A avaliação psicológica, como se apresenta atualmente, é considerada um processo amplo que requer competências profissionais e habilidades acadêmicas específicas do profissional psicólogo e se constitui como campo de conhecimento específico reconhecido internacionalmente (cf. CFP, 2013).

\subsection{O normal e o justo na avaliação: Questões éticas na avaliação psicológica}

Uma das lacunas encontradas no aspecto ético é a necessidade de uma melhor qualificação e formação dos profissionais que pretendem trabalhar com avaliação psicológica. A falta de treinamento adequado, o desconhecimento da psicometria e o uso inadequado dos instrumentos sem entendimento teórico/técnico do que está fazendo são algumas das causas das faltas éticas cometidas pelos profissionais psicólogos (Bueno \& Peixoto, 2018).

Tratando-se de Ética, esta, é importante por situar-se em uma filosofia moral, capaz de promover uma reflexão, discussão e problematização dos valores morais. Valores estes que guiam os princípios que motivam, orientam ou distorcem o comportamento humano. Determina ainda preceitos e normas voltadas às questões morais e juízos de valor que regem um indivíduo ou grupo social (Chauí, 1995; Wechsler, 2019)

Para Muniz (2018) a consciência ética é percebida pelo sujeito quando se compara o que é e o que deveria ser. E partindo desse viés, a ética profissional aborda questões que ultrapassam o campo profissional em si pois tratará de temas como aborto, discriminação, gênero que exigem uma reflexão ética (além da técnica) do profissional.

A profissão de psicólogo é pautada pelo Código de Ética Profissional do Psicólogo (CEP) elaborado em 2005 (Resolução n 10/2005), com o objetivo de "fomentar a autorreflexão exigida de cada indivíduo acerca de sua práxis, de modo a responsabilizá-lo, pessoal e coletivamente, por ações e suas consequências no exercício profissional" (CFP, 2005, p.5). A atuação do psicólogo 
deve respeitar e se fundamentar nos preceitos éticos, princípios e responsabilidades elencadas no código de ética profissional do psicólogo.

Assim sendo, o CEP convida o profissional a refletir sobre sua prática, tornando-o consciente da responsabilidade que tem com sua práxis seja de forma individual ou coletiva e das consequências de suas ações. Este Código traz ainda que essa reflexão deve ser contínua uma vez que as sociedades mudam, as profissões se transformam e o entendimento sobre o ser humano se modifica. Portanto, não pode ser visto como um documento imutável ou normativo de uma conduta universal.

O CEP em seu art. $1^{\circ}$ versa que entre os deveres do profissional psicólogo está "prestar serviços psicológicos de qualidade em condições dignas e apropriadas à natureza desses serviços, utilizando princípios, conhecimentos e técnicas reconhecidamente fundamentados na ciência psicológica, na ética e na legislação profissional" (CFP, 2005, p.8).

Nessa perspectiva, a Avaliação Psicológica não deve ser utilizada como forma de comparação entre grupos sociais ou ainda como forma de rotular ou classificar o sujeito. Hoje procura-se enfatizar questões como justiça, direitos humanos e equidade entre as pessoas que participam desse processo. Um dos reforços da resolução CFP 009/2018 é justamente trazer a questão da justiça e dos direitos humanos na avaliação psicológica.

O CFP alerta ainda na resolução CFP 009/2018 que é vedado na produção, validação, tradução, adaptação, normatização, comercialização e aplicação de testes psicológicos atividade que possam:

a) caracterizar negligência, preconceito, crueldade, violência ou opressão;

b) induzir convicções políticas, filosóficas, morais, ideológicas, religiosas, raciais, de orientação sexual e identidade de gênero;

c) favorecer o uso de conhecimento da ciência psicológica e normatizar a utilização de práticas psicológicas como instrumentos de castigo, tortura ou qualquer forma de violência (CFP, 2018, p.14).

O psicólogo que atua na área de avaliação deve ter conhecimento não somente sobre o Código de Ética Profissional do Psicólogo, mas também de todas as Resoluções do CFP que normatizam essa área, uma vez que se trata de uma área bem regulamentada.

Segundo Muniz (2018) muitas Resoluções já foram modificadas ou revogadas demonstrando o cuidado do CFP e Conselho Regional de Psicologia (CRP) regionais nas demandas da área e da sociedade confirmando o caráter dinâmico das questões éticas. Com isso, à avaliação psicológica pode contribuir para a responder a qualidade de vida das pessoas quando a intervenção é feita de forma adequada, mas também, pode causar danos quando aplicada por profissionais não qualificados ou através do uso de instrumentos não apropriados a realidade dos sujeitos avaliados.

Essa nova perspectiva exige que os profissionais de psicologia estejam mais atentos à formação adequada em avaliação psicológica e testagem, uma vez que a partir dos resultados Rev. Psicol Saúde e Debate. Mar., 2021:7(1): 149-170. 
obtidos através desses procedimentos serão propostas intervenções psicológicas aos sujeitos avaliados.

Outra perspectiva apresentada por Wechsler (2019), refere-se a importância em promover uma discussão da ética não só em nível de deontologia, mas também em seus aspectos émicos respeitando a cultura de cada local. A deontologia deriva da ética e é focada nos deveres e normas dentro da profissão.

No que se refere ao aspecto "êmico, trata-se da representação de um construto psicológico dentro de uma determinada cultura, ou seja, como os membros de uma cultura entendem as suas manifestações" (Wechsler, 2019, p. 153). Essa discussão se torna importante por exemplo quando se trata da construção e adaptação de testes psicológicos para diferentes países e culturas.

Para Muniz (2018) a complexidade da área de avaliação psicológica e a necessidade de novos conhecimentos para responder às demandas refletem a necessidade e importância do desenvolvimento de competências que sustentem a prática ética do profissional nesta área através do investimento na formação. E para além da formação em avaliação psicológica uma formação ética, consistente e permanente.

Como já dito anteriormente, um dos problemas enfrentados pelo CFP é a infração do Código de Ética nos processos de avaliação psicológica. Zaia, Oliveira e Nakano (2018) afirmam que nos três últimos números do Jornal do CFP, no período de 2004 a 2016, 60\% dos processos estavam relacionados a avaliação psicológica, onde se destacam queixas em relação à má elaboração de laudos psicológicos, má utilização de testes psicológicos e irregularidades no processo de avaliação psicológica. Dessa forma, as autoras destacam a importância em investimentos na formação em avaliação psicológica que não deve ocorrer somente na graduação, é necessário que o profissional realize cursos de atualização e que invista em sua capacitação em uma formação continuada evitando assim, resultados de imperícia e má conduta profissional.

\subsection{Discussões e direções futuras}

O nível de desenvolvimento alcançado na área de avaliação psicológica no Brasil não é encontrado, ainda em nenhum outro país da América do Sul. Todavia, se comparado com países desenvolvidos ainda há muito o que evoluir no que se refere as características dos instrumentos, à formação dos docentes e profissionais da área de acordo com Wechsler et al (2014, p. 126).

É possível perceber uma reflexão sobre as práticas inadequadas, proposição de alternativas e a retomada do desenvolvimento da área no Brasil a partir da mudança ocorrida na área com a criação de associações profissionais ligadas a avaliação psicológica (IBAP e AsBRo), implantação do SATEPSI e a criação de diversos laboratórios e linhas de pesquisa em avaliação. 
De acordo com Primi (2010) há maior investimento no desenvolvimento e aperfeiçoamento de instrumentos de avaliação, melhorando sua qualidade técnica e proporcionando o crescimento do mercado de testes e a disseminação de seus parâmetros psicométricos de qualidade.

Entretanto, mesmo diante dessa retomada da área vários aspectos ainda podem ser desenvolvidos no Brasil. Para Bueno e Peixoto (2018), é necessário fortalecer o compromisso com as práticas de inclusão social e respeito aos direitos humanos, a utilização de recursos informatizados, emprego de análises estatísticas mais robustas para análise de grandes quantidades de dados (big data), e principalmente a melhoria na formação em avaliação e o aprimoramento do SATEPSI.

Um dos aspectos essenciais para esse novo direcionamento da área de avaliação psicológica é a formação acadêmica dos profissionais que trabalham na área. Diante das novas demandas profissionais e sociais e com a ampliação das possibilidades de atuação é necessário fomentar a educação continuada na área e o aprimoramento do ensino nas universidades brasileiras.

Para Noronha et al (2002) a formação deve cobrir pelo menos os seguintes domínios: a) teoria da medida e psicometria; b) avaliação da inteligência; c) avaliação da personalidade e d) práticas integrativas de planejamento, execução e elaboração dos documentos.

Para Bueno e Peixoto (2018), alguns estudos apontam problemas que dificultam a melhoria da qualidade da formação: a) a permanência de uma visão limitada e preconceituosa em relação à avaliação psicológica; b) a falta de qualificação dos professores; c) a carga horária reduzida das disciplinas de avaliação psicológica e d) o ensino descontextualizado e apenas procedimentais de testes psicológicos.

Na concepção de Nakano e Alves (2019), além da revisão das cargas horárias e ementas das disciplinas de avaliação é necessário verificar a disponibilidade de recursos materiais - muitas vezes desatualizados ou em quantidade insuficiente - e de local adequado para a aplicação de testes psicológicos nas instituições de ensino.

De acordo com Primi (2018) uma discussão que ocorreu internamente na comissão consultiva do SATEPSI e que atualmente está no âmbito profissional é a questão do uso privativo dos testes psicológicos pelos psicólogos. Há duas vertentes de posicionamento sobre esse assunto: a) posição a favor do uso privativo por profissionais que defendem que todos os testes devem ser de uso exclusivo de psicólogos e b) posição favorável à abertura parcial por entender que alguns testes com características específicas poderiam ter uso compartilhado com outras profissões específicas como medicina e educação.

Até o momento, a maioria dos psicólogos ainda defende a primeira opção, sustentando a ideia de que é necessário conhecimento especializado para o uso adequado dos instrumentos e por defender que se outros profissionais precisam de algum tipo de informação obtida através de avaliação psicológica devem solicitar ao psicólogo. 
A outra vertente discute questões como: se profissionais de outras áreas tivessem uma formação como Pós-graduação que sustentasse teórica e metodologicamente, isso não os habilitaria a usar esses instrumentos? Este, entre outros exemplos, motiva a posição da abertura parcial do uso dos testes. Com isso, é importante mencionar que a abertura parcial do uso dos testes psicológicos de certa forma já existe, uma vez que o instrumento Neupsilin (instrumento de avaliação neuropsicológica breve) pode ser usado por psicólogos e fonoaudiólogos após análise técnica conjunta e entendimento consensual entre os conselhos federais de Psicologia e Fonoaudiologia.

A conclusão dessa discussão gerou a resolução conjunta CFP/CFF n0ㅣ 012017 que afirma que o Neupsilin pode ser usado por psicólogos e fonoaudiólogos para propósitos específicos de cada especialidade. Essa resolução abre, portanto, um precedente para a mudança do modelo de uso privativo (Primi, 2018).

Além desse aspecto, a Lei federal no 4.119 de 1962, que versa sobre o uso privativo de métodos e técnicas por psicólogos, afirma que a restrição ao uso dos testes existe somente quando usado para as finalidades definidas na referida lei que são: psicodiagnóstico, psicologia clínica, orientação psicoeducacional, seleção e orientação profissional. A restrição não é do instrumento em si, mas do seu uso para determinadas finalidades. Havendo uma outra possibilidade de uso fora das citadas acima, como por exemplo pesquisas acadêmicas, esta não é abrangida pela restrição da lei.

A própria comercialização dos testes também não encontra respaldo na lei (Brasil, 1962). Sendo assim, embora a maioria dos psicólogos mantenha a posição do uso privativo, já há uma certa abertura a partir da resolução conjunta do Neupsilin e da abertura encontrada na lei 4.119 de 1962. Entretanto deve-se chamar a atenção para casos que de fato se configuram como exercício ilegal da profissão como o uso por administradores em processos seletivos ou médicos que realizam avaliação psicológica, pois essas são finalidades que estão especificadas na lei de 1962 (Primi, 2018).

Um outro caminho que a avaliação psicológica tem tomado é dos comportamentos digitais, ou seja, características pessoais que são analisadas a partir das preferências nas redes sociais como postagens e likes. Alguns autores da Universidade de Cambridge realizaram estudos baseados nas coletas de dados do facebook e a partir desses dados utilizaram técnicas estatísticas de agrupamento de dados para predizer características de personalidade (Kosinski, Stillwell, \& Grapel, 2013).

Para Primi (2018, p. 94) "os comportamentos digitais refletem as caraterísticas pessoais do agente, isto é, variáveis latentes representando os traços de personalidade, interesse ou Inteligência". A diferença entre os testes tradicionais estaria nos indicadores e na técnica de agregação. Os sistemas automatizados usam armazenamento constante das informações o que 
gera um imenso banco de dados (big data) de comportamento digital dos usuários podendo trazer informações sobre consumo, saúde e preferências.

Esses estudos ajudarão a área de inteligência artificial que busca descobrir de forma automática padrões nos dados e permitir a previsão de variáveis relevantes. E no caso do avanço desses estudos e pesquisas se faz necessário a participação do profissional psicólogo para que possa dar sentido às informações coletadas dos usuários já se que tratam de perfis psicológicos (Primi, 2018).

É possível perceber o caminho que a avaliação psicológica tem traçado nas últimas décadas e seus avanços a partir das ações do CFP e do SATEPSI. Mas ainda há muito a ser feito. A avaliação psicológica é muito mais ampla que consultório ou práticas isoladas. É um processo amplo, com grande potencial de expansão para novas realidades que se colocam como a avaliação online, comportamento digital, inteligência artificial e uma participação interdisciplinar em suas ações.

Figura 1: Direções futuras para a área de avaliação psicológica.

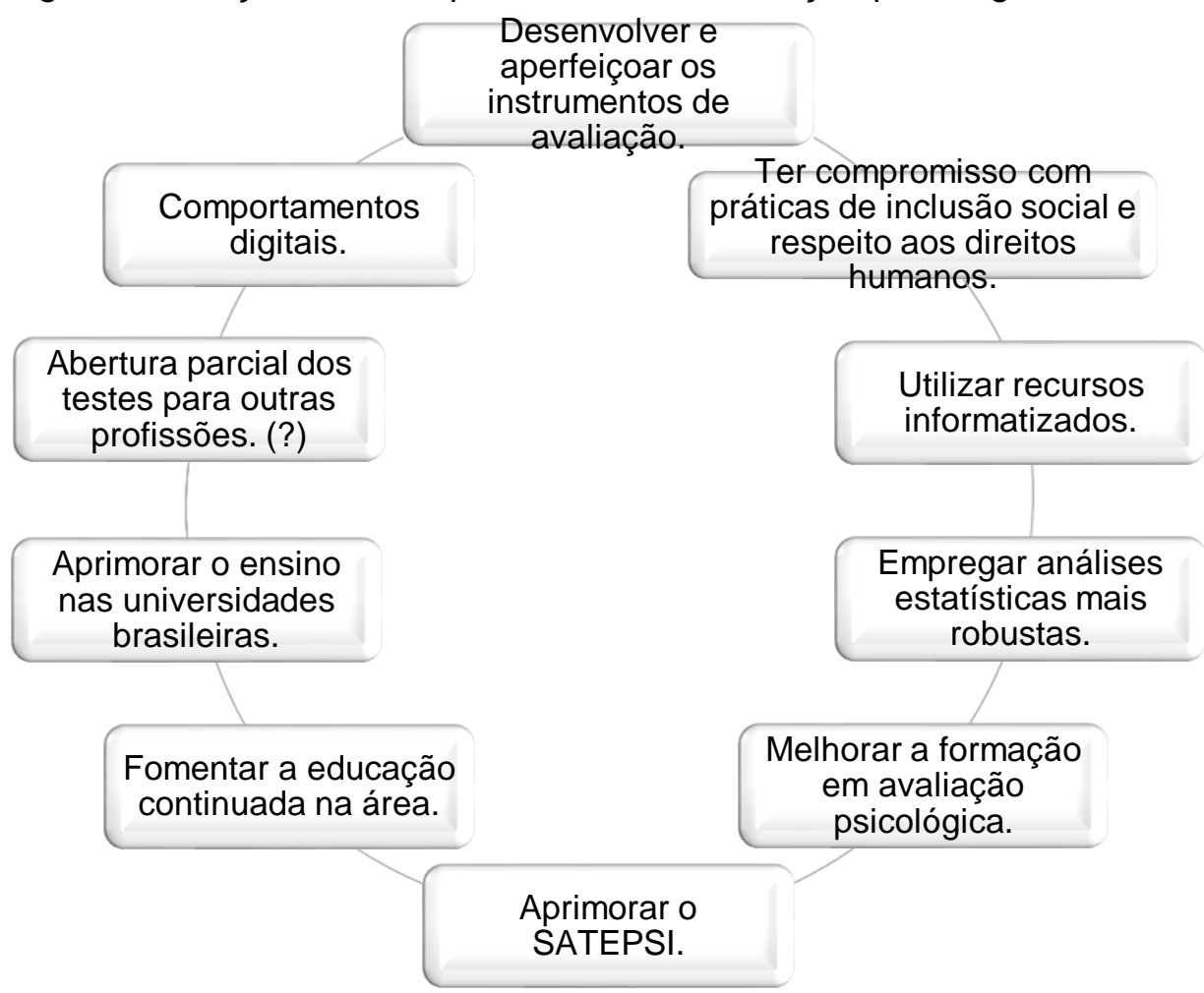

Nota: Elaborado pelos autores.

\section{CONSIDERAÇÕES FINAIS}

Seguramente a área de avaliação psicológica teve grande avanço nos últimos anos fomentado principalmente pelas ações do CFP e atuação do Satepsi. O nível que alcançamos no país é destaque na América Latina, mas ainda há muito o que evoluir para atingir os níveis de países 
desenvolvidos no que diz respeito à formação dos docentes, pesquisadores e profissionais que atuam na área.

Há ainda que se reconhecer o esforço em pensar a avaliação psicológica pautada na ética através das várias resoluções elaboradas pelo CFP numa tentativa de diminuir os processos éticos que chegam para análise e que em grande parte são da área de avaliação psicológica.

Por outro lado, a formação dos psicólogos para atuar com avaliação psicológica é um dos pontos de atenção e preocupação. Além de carga horária insuficiente de disciplinas, pode ser apontado como fragilidade o ensino descontextualizado e apenas procedimentais de testes psicológicos e falta de recursos materiais.

Sendo assim, é preciso continuar investindo na formação dos psicólogos que trabalham na área e construção de orientações de boas práticas da Psicologia com outras ciências para que possamos contribuir com o nosso fazer científico para uma psicologia mais moderna e voltada para as necessidades atuais. Dessa forma será possível melhorar a qualidade do serviço psicológico prestado pela área de avaliação psicológica à sociedade.

\section{REFERÊNCIAS}

Alchieri, J. C. \& Cruz, R. M. (2003) Avaliação psicológica: conceito, métodos e instrumentos. São Paulo: Casa do Psicólogo.

Brasil (1962). Lei 4.119, de 27 de agosto de 1962. Dispõe sobre os cursos de formação em psicologia e regulamenta a profissão de psicólogo. Publicada em 05 de setembro de 1962. Diário Oficial da União. Recuperado de http://www.planalto.gov.br/ccivil_03/leis/19501969//4119.htm

Brasil (1964). Decreto 53.464, de 21 de janeiro de 1964. Regulamenta a Lei $n^{\circ} 4.119$, de 27 de agosto de 1962, que dispõe sobre a profissão de psicólogo. Publicado em 24 de janeiro de 1964. Diário Oficial da União. Recuperado de http://www.planalto.gov.br/ccivil_03/decreto/1950-1969/D53464.htm

Bueno, J. M. H., \& Peixoto, E. M. (2018). Avaliação Psicológica no Brasil e no Mundo. Psicologia: Ciência e Profissão, 38(n.spe), 108-121. https://doi.org/10.1590/1982-3703000208878

Bueno, J. M. H., \& Ricarte, M. D. (2017). Aspectos históricos da testagem psicológica: contexto internacional e nacional. In: M. R. C. Lins, \& J. C. Borsa (Orgs.), Avaliação psicológica: Aspectos teóricos e práticos (pp. 38-55). Petrópolis, RJ: Vozes.

Conselho Federal de Psicologia (2005). Código de ética profissional do psicólogo. Brasília, DF. Recuperado de https://site.cfp.org.br/wp-content/uploads/2012/07/codigo-de-eticapsicologia.pdf

Conselho Federal de Psicologia (2013). Cartilha Avaliação Psicológica. Recuperado de http://satepsi.cfp.org.br/docs/cartilha.pdf

Conselho Federal de Psicologia (2018). Resolução no 009. Brasília, DF. Recuperado de http://satepsi.cfp.org.br/docs/Resolu\%C3\%A7\%C3\%A3o-CFP-n\%C2\%BA-09-2018-comanexo.pdf 
Conselho Federal de Psicologia (2019). Resolução no 006. Brasília, DF. Recuperado de https://atosoficiais.com.br/lei/elaboracao-de-documentos-escritos-produzidos-pelo-psicologodecorrentes-de-avaliacao-psicologica-cfp?origin=instituicao

Conselho Federal de Psicologia, Conselho Federal de Fonoaudiologia (2017). Resolução Conjunta №. 01/2017. Recuperado de https://www.fonoaudiologia.org.br/cffa/wpcontent/uploads/2013/07/res-conjunta-neupsilim.pdf

Faiad, C.; Pasquali, L.; Oliveira, K. L. (2019) Histórico da avaliação psicológica no mundo. In M. N. Baptista (Org.).Compêndio de avaliação psicológica. Petrópolis, RJ: Vozes.

Kosinski, M., Stillwell, D., \& Graepel, T. (2013). Private traits and attributes are predictable from digital records of human behavior. Proceedings of the National Academy of Sciences, 110(15), 5802-5805. Recuperado de https://doi.org/10.1073/ pnas. 1218772110

Mansur-Alves, M., Silva, R. S., \& Fernandes, S. C. Ávila. (2016). Impact of the Psychological Testing Assessment System (SATEPSI) for Scientific Publications in Psychological Assessment. Psico-USF, 21(1), 179-188. https://dx.doi.org/10.1590/1413-82712016210115

Medeiros, G. A. (2002) Por uma ética na saúde: algumas reflexões sobre a ética e o ser ético na atuação do psicólogo. Psicol. cienc. prof. [online], vol.22, n.1, pp. 30-37. ISSN 1414-9893. http://dx.doi.org/10.1590/S1414-98932002000100005.

Muniz, M. (2018). Ética na avaliação psicológica: velhas questões, novas reflexões. Psicologia: Ciência e Profissão, 38 (spe), 133-146. Recuperado de https://dx.doi.org/10.1590/19823703000209682

Nakano, T. C. \& Alves, R. J. R. (2019) Avaliação Psicológica no Brasil. In M. N. Baptista (Org.).Compêndio de avaliação psicológica. Petrópolis, RJ: Vozes.

Noronha, A. P., \& Alchieri, J. C. (2002). Reflexões sobre os instrumentos de avaliação psicológica. In R. Primi (Ed.), Temas em avaliação psicológica (pp. 7-16). Campinas: Ibap.

Noronha, A. P. P., Primi, R., \& Alchieri, J. C. (2004). Parâmetros psicométricos: uma análise de testes psicológicos comercializados no Brasil. Psicologia: Ciência e Profissão, 24(4), 8899. https://dx.doi.org/10.1590/S1414-98932004000400011

Noronha, A. P. P., \& Reppold, C. T. (2010). Considerações sobre a avaliação Psicológica no Brasil. Psicologia: Ciência e Profissão, 30 (spe), 192-201. https://dx.doi.org/10.1590/S141498932010000500009

Noronha, A. P. P., Ziviani, C., Hutz, C. S., Bandeira, D., Custódio, E. M., Alves, I. B., Alchieri, J. C., Borges, L. O., Pasquali, L., Primi, R., \& Domingues, S. (2002). Em defesa da avaliação psicológica. Avaliação Psicológica, 1(2), 173-174. Recuperado de 13 de janeiro de 2020, de http://pepsic.bvsalud.org/scielo.php?script=sci arttext\&pid=S1677$04712002000200010 \& \operatorname{lng}=\mathrm{pt} \& \ln \mathrm{n}=\mathrm{pt}$.

Pasquali, L. (2010). Instrumentação psicológica: fundamentos e práticas. Porto Alegre. Artmed.

Pasquali, L. (2001). Técnicas de Exame Psicológico - TEP Vol. I: Fundamentos das Técnicas Psicológicas. São Paulo: Casa do Psicólogo / Conselho Federal de Psicologia

Primi, R. (2010). Avaliação psicológica no Brasil: fundamentos, situação atual e direções para o futuro. Psicologia: Teoria e Pesquisa, 26(spe), 25-35. https://dx.doi.org/10.1590/S010237722010000500003 
Primi, R. (2018) Avaliação psicológica no século XXI: De onde viemos e para onde vamos. Psicologia: Ciência e Profissão, 38 (spe), 87-97. Recuperado de: http://dx.doi.org/10.1590/1982-3703000209814

Primi, R., \& Nunes, C. H. S. (2010). O Satepsi: Desafios e propostas de aprimoramento. In: Conselho Federal de Psicologia - CFP (Ed.), Avaliação psicológica: Diretrizes na regulamentação da profissão (pp. 129-148). Brasília, DF.

Reppold, C. T., \& Noronha, A. P. P. (2018). Impacto dos 15 Anos do Satepsi na Avaliação Psicológica Brasileira. Psicologia: Ciência e Profissão, 38(spe), 6-15. Recuperado de https://dx.doi.org/10.1590/1982-3703000208638

Reppold, C. T., Serafini, A. J., Ramires, D. A., \& Gurgel, L. G. (2017). Análise dos manuais psicológicos aprovados pelo SATEPSI para avaliação de crianças e adolescentes no Brasil. Avaliação Psicológica, 16(1), $\quad 19-28$. Recuperado de https://dx.doi.org/10.15689/ap.2017.1601.03

Reppold, C. T., Zanini, D. S., \& Noronha, A. P. P (2019) O que é avaliação psicológica. In M. N. Baptista (Org.).Compêndio de avaliação psicológica. Petrópolis, RJ: Vozes.

Wechsler, S. M., Hutz, C. S., \& Primi, R. (2019) O desenvolvimento da avaliação psicológica no Brasil: Avanços históricos e desafios. Avaliação Psicológica, 18(2), 121-128. Recuperado de https://dx.doi.org/10.15689/ap.2019.1802.15466.02

Wechsler, S. M (2019) Ética na avaliação psicológica: uma perspectiva internacional. In M. N. Baptista (Org.).Compêndio de avaliação psicológica. Petrópolis, RJ: Vozes.

Wechsler, S. M. (1999). Guia de procedimentos éticos para a avaliação psicológica. In S. M. Wechsler, R. L. Guzzo (Orgs.), Avaliação psicológica: perspectiva internacional (pp.133-141). São Paulo: Casa do Psicólogo.

Zaia, P., Oliveira, K. S., \& Nakano, T. C. (2018). Análise dos Processos Éticos Publicados no Jornal do Conselho Federal de Psicologia. Psicologia: Ciência e Profissão, 38(1), 821. https://dx.doi.org/10.1590/1982-3703003532016 